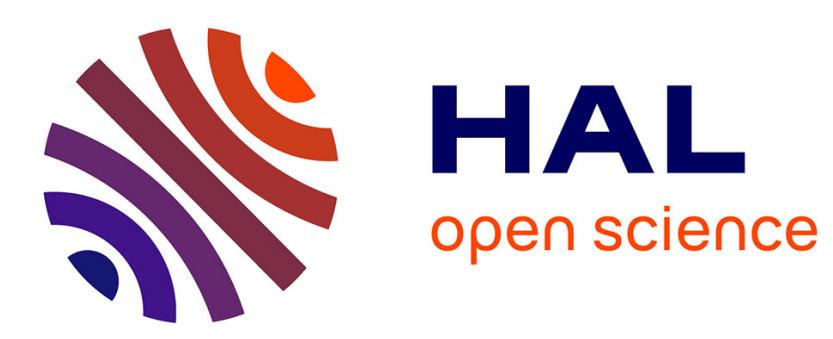

\title{
Microwave Dielectric Spectroscopy of a Single Biological Cell with Improved Sensitivity up to $40 \mathrm{GHz}$
}

\author{
Wenli Chen, David Dubuc, Katia Grenier
}

\section{To cite this version:}

Wenli Chen, David Dubuc, Katia Grenier. Microwave Dielectric Spectroscopy of a Single Biological Cell with Improved Sensitivity up to $40 \mathrm{GHz}$. IEEE International Microwave Symposium (IMS), May 2015, Phoenix, United States. 10.1109/MWSYM.2015.7166974 . hal-01951669

HAL Id: hal-01951669

https://hal.laas.fr/hal-01951669

Submitted on 11 Dec 2018

HAL is a multi-disciplinary open access archive for the deposit and dissemination of scientific research documents, whether they are published or not. The documents may come from teaching and research institutions in France or abroad, or from public or private research centers.
L'archive ouverte pluridisciplinaire HAL, est destinée au dépôt et à la diffusion de documents scientifiques de niveau recherche, publiés ou non, émanant des établissements d'enseignement et de recherche français ou étrangers, des laboratoires publics ou privés. 


\title{
Microwave Dielectric Spectroscopy of a Single Biological Cell with Improved Sensitivity up to $40 \mathrm{GHz}$
}

\author{
Wenli Chen, David Dubuc and Katia Grenier \\ CNRS, LAAS, Univ. de Toulouse, 7 avenue du colonel Roche, F-31400 Toulouse, France
}

\begin{abstract}
This paper presents the sensitivity optimization of a microwave biosensor dedicated to the analysis of a single living biological cell from $40 \mathrm{MHz}$ to $40 \mathrm{GHz}$, directly in its culture medium. To enhance the sensor sensitivity, different capacitive gap located in the center of the biosensor, below the cell position, have been evaluated with different beads sizes. The best capacitive and conductive contrasts have been reached for a gap width of $5 \mu \mathrm{m}$ with beads exhibiting diameters of 10 and $20 \mu \mathrm{m}$, due to electromagnetic field penetration in the beads. Contrasts improvement of 40 and $60 \%$ have been achieved with standard deviations in the order of only $4 \%$ and $6 \%$ for the capacitive and conductive contrasts respectively. This sensor therefore permits to measure single living biological cells directly in their culture medium with capacitive and conductive contrasts of $0.4 \mathrm{fF}$ at 5 $\mathrm{GHz}$ and $85 \mu \mathrm{S}$ at $40 \mathrm{GHz}$, and associated standard deviations estimated at $7 \%$ and $14 \%$ respectively.
\end{abstract}

Index Terms - Microwave dielectric spectroscopy, biosensor, coplanar waveguide, biology, cell.

\section{INTRODUCTION}

Actual routine instrumentations for cellular analysis are based on optical detection methods. Microscopy and cytometry involves staining or fluorescent techniques, which are indeed very efficient especially in terms of precision and specificity. They however suffer from invasivity with respect to the living analyzed cells, cost and time-efficiency [1].

Among complementary cellular analyzing techniques [2], electrical ones present important advantages. Microwave dielectric spectroscopy is particularly noticeable due to its numerous assets [3]: the technique is naturally non-invasive for the cells, as well as contact free, harmful free and nonionizing. It is also miniature and therefore compatible with lab-on-chip applications [3]-[5]. Cells may also be directly analyzed in their culture medium during biological processes [6]. Microwave dielectric spectroscopy constitutes therefore a promising candidate for non-invasive cellular analysis in real time.

Both analyses at the population and at the single cell level are of interest for the biologist and medical communities [7]. So far, the microwave sensing technique has been evaluated mainly at the cell population level [3], [8]-[9] and more recently at the single cell level with a microwave interferometric architecture [10], or in broadband with a capacitive topology from $40 \mathrm{MHz}$ up to $40 \mathrm{GHz}$ [11].
This paper therefore deals with a similar capacitive sensor topology for broadband single cell analysis with microwave dielectric spectroscopy and focus on the optimization of the biosensor sensitivity and repeatability of measurements.

\section{BIOSENSOR ARCHITECTURE AND MICROFABRICATION}

The device developed to perform the microwave dielectric spectroscopy of a single biological cell is presented in Fig. 1. It includes a coplanar waveguide with a capacitive gap in the center. Perpendicularly placed on top is a microfluidic channel, with a mechanical trap in its center. This trap is used to precisely immobilize a biological cell right above the capacitive gap, where the electromagnetic fields are focused.

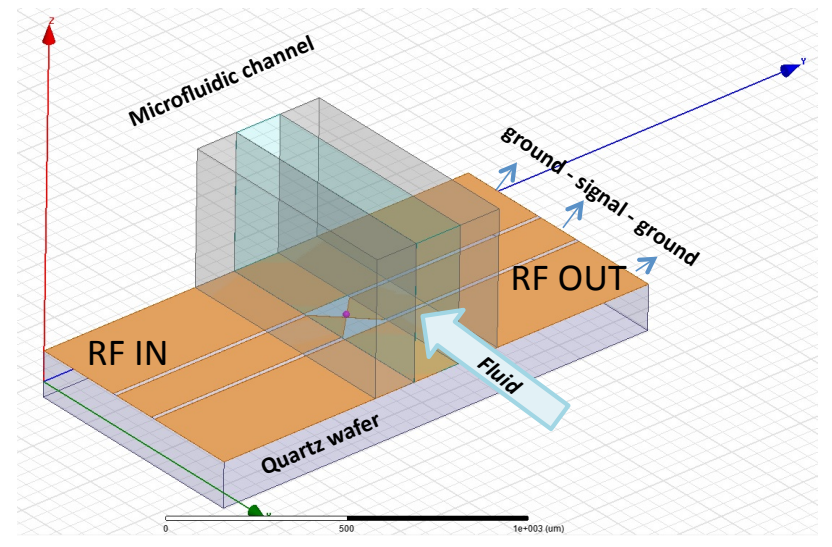

Fig. 1. HFSS view of the biosensor composed of a coplanar waveguide with a microfluidic channel perpendicularly placed on top, which integrates a mechanical trap. The simulated cell is in red.

Fig. 2 presents a zoomed photography of the trap with a polystyrene bead blocked inside. Due to the liquid in the channel, it is not possible to clearly visualize both bead in the blocker and metallization. The waveguide is realized with a 0.3um thick gold layer, whereas trap and microfluidic channel are constituted of SU-8, which has been polymerized after photolithography.

Several biosensors configurations have been fabricated. Both gap and trap sizes have been modified in order to optimize the sensor in terms of sensitivity and trapping efficiency. This paper focuses on the study of sensitivity and repeatability of microwave measurements. 


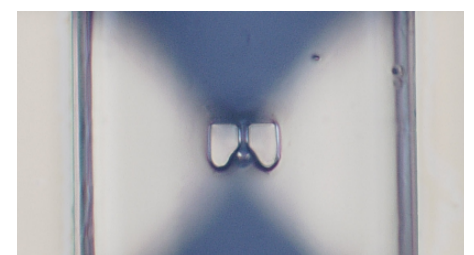

Fig. 2. Photography of a single bead blocked in the trap, located on top of the capacitive gap.

\section{SENSITIVITY OPTIMIZATION AND REPEATABILITY OF MEASUREMENTS WITH POLYSTYRENE BEADS}

To assess the sensitivity, biosensors with different size of capacitive gaps have been simulated, fabricated and measured and evaluated with polystyrene beads in de-ionized water. Beads present the interest of being a simple model with constant permittivity and conductivity values compare to biological cells. Gap widths correspond to 5 and $10 \mu \mathrm{m}$ respectively and have been defined due to the averaged $15 \mu \mathrm{m}$ diameter of the targeted biological cells. Fig. 3 and 4 present the extracted capacitive and conductive contrasts (similar extraction method as in [11]) for two beads diameters: 10 and $20 \mu \mathrm{m}$. Contrasts have been calculated compare to the host liquid medium, DI water. Therefore, the 'zero' line in Fig. 3 and 4 corresponds to the reference DI water. Repeatitivity of the measurements have also been performed in order to extract the standard deviation for all cases.

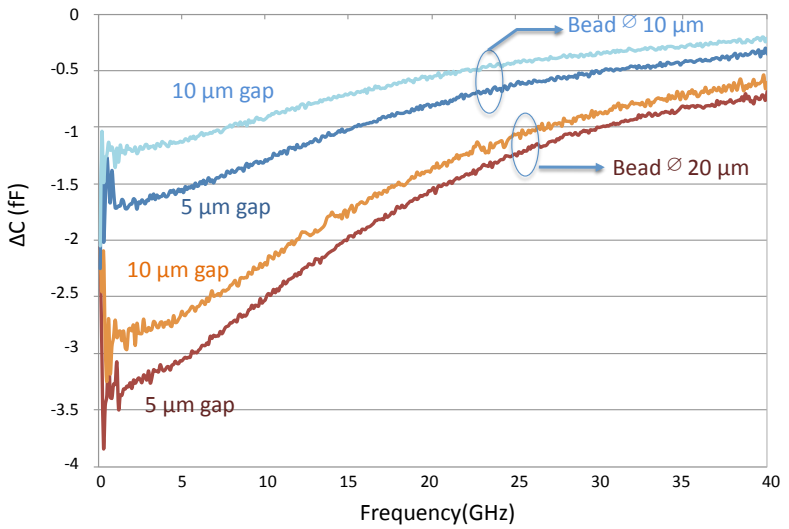

Fig. 3. Capacitive contrast of polystyrene beads of 10 and $20 \mu \mathrm{m}$ of diameter for the 5 and $10 \mu \mathrm{m}$ widths of sensor's gap.

The results are summarized in Table 1. As one may expect due to size reduction of the beads, the $10 \mu \mathrm{m}$ diameter one presents lower capacitive and conductive contrasts compare to the $20 \mu \mathrm{m}$ diameter bead. Measurements are also very repetitive as the standard deviations are in the order of $4 \%$ and $6 \%$ for the capacitive and conductive contrasts respectively. Moreover, in all configurations, the $5 \mu \mathrm{m}$ wide gap presents the largest contrast compare to the $10 \mu \mathrm{m}$ one. Improvements close to $40 \%$ and $50 \%$ are reached on the capacitive and conductive contrasts respectively in the case of the $10 \mu \mathrm{m}$ diameter bead.

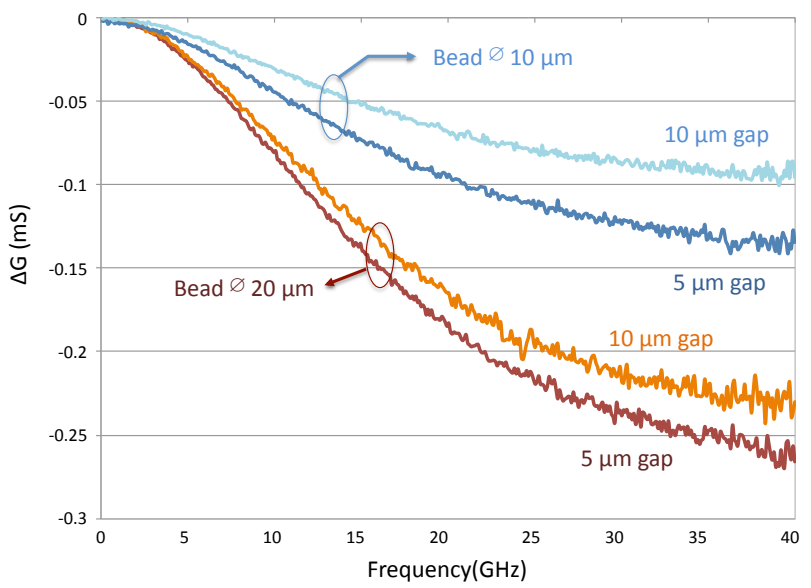

Fig. 4. Conductive contrast of polystyrene beads of 10 and $20 \mu \mathrm{m}$ of diameter for the 5 and $10 \mu \mathrm{m}$ widths of sensor's gap.

Table 1. Summary of capacitive and conductive contrasts at 5 and $40 \mathrm{GHz}$ respectively, with respect to gap and bead sizes. Standard deviations in bracket.

\begin{tabular}{|l|c|c|c|c|}
\hline \multirow{2}{*}{} & \multicolumn{2}{|c|}{$\Delta \mathrm{C}(\mathrm{fF}) @ 5 \mathrm{GHz}$} & \multicolumn{2}{c|}{$\Delta \mathrm{G}(\mathrm{mS}) @ 40 \mathrm{GHz}$} \\
\cline { 2 - 5 } & $\Phi 10 \mu \mathrm{m}$ & $\Phi 20 \mu \mathrm{m}$ & $\Phi 10 \mu \mathrm{m}$ & $\Phi 20 \mu \mathrm{m}$ \\
\hline Gap $5 \mu \mathrm{m}$ & $-1.53(0.06)$ & $-3.05(0.05)$ & $-0.135(0.009)$ & $-0.225(0.009)$ \\
\hline Gap $10 \mu \mathrm{m}$ & $-1.12(0.05)$ & $-2.53(0.09)$ & $-0.09(0.009)$ & $-0.26(0.01)$ \\
\hline
\end{tabular}

This result may be explained by the variation of electromagnetic field penetration inside the bead and host medium, as shown in Fig. 5 with simulations performed with the finite element software $\operatorname{HFSS}^{\odot}$ for both 5 and $10 \mu \mathrm{m}$ wide gaps configurations. Placement of different circles with diameters ranging from 10 to $20 \mu \mathrm{m}$ is indicated on the figure in order to better estimate the bead location and fields distribution. The strength intensity of the electromagnetic field presents an increase of $63 \%$ with the $5 \mu \mathrm{m}$ gap configuration compare to the $10 \mu \mathrm{m}$ one, in the $10 \mu \mathrm{m}$ circle.
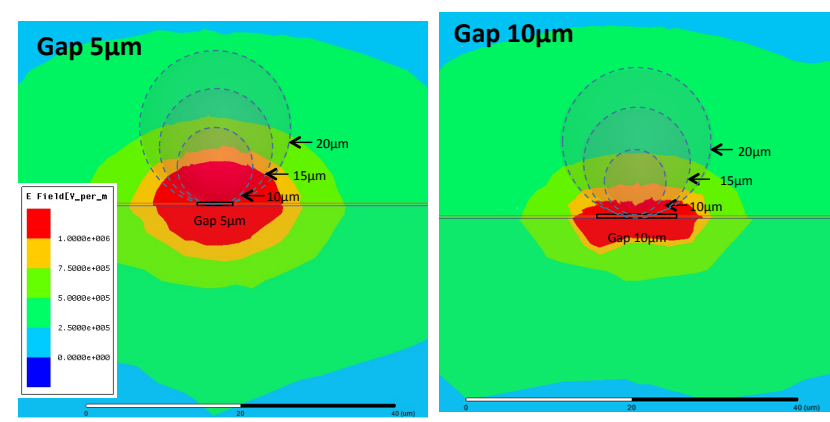

Fig. 5. Electromagnetic field distribution depending of gap width. 
Based on this study and to maximize the sensitivity of the biosensor, the capacitive gap size of $5 \mu \mathrm{m}$ is prefered and employed in the next section, which is dedicated to the RF measurement of single biological cells directly in their culture medium.

\section{Microwave Dielectric Spectroscopy of a Single Bead AND Biological CELl in Culture Medium}

RF measurements of single biological cells have been performed. Used cells correspond to the THP1, a human monocytic cell line for leukemia investigations. They present an average cell diameter of $15.4 \mu \mathrm{m}$. The traditional cell culture medium is the Roswell Park Memorial Institute one (RPMI) with $10 \%$ of Fetal Bovine Serum (FBS).

Several individual living cells have been measured and their average contrasts are given in Fig. 6, as well as for $10 \mu \mathrm{m}$ polystyrene beads in the same host medium as the cells. The reference used in these cases is the culture medium, which in Fig. 6 corresponds to the "zero" line.

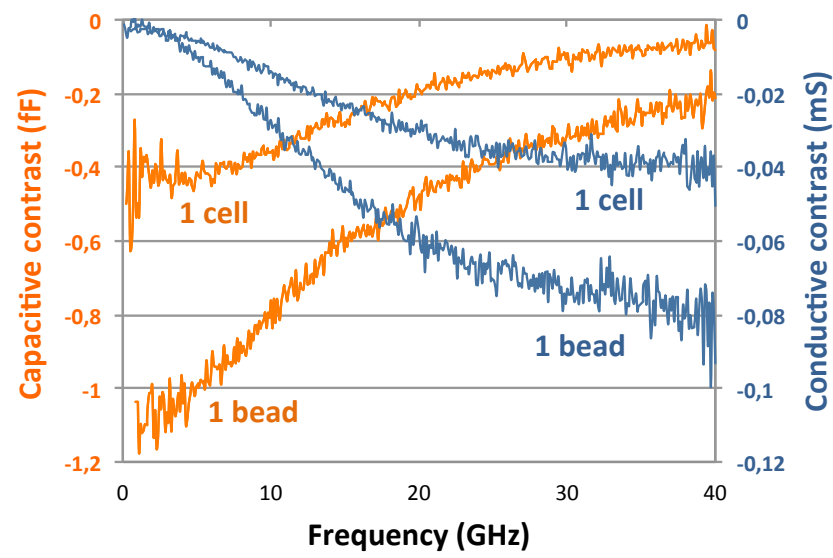

Fig. 6. Capacitive and conductive contrasts of a single polystyrene bead and a single biological cell in cell culture medium (RPMI added with $10 \%$ of FBS)

The capacitive contrast of the cell is lower than the bead's one. This is related to their respective relative effective permittivities, which is close to the culture medium one in the case of cell, and thus to water (from 80 to 30 depending on the frequency), whereas polystyrene beads present a permittivity close to $2.4-2.7$.

Table 2 indicates the summary of measured data for both single beads and cells in culture medium. Standard deviations for the capacitive and conductive contrasts have been estimated at $7 \%$ and $14 \%$ respectively in the case of the single cells. These values are larger than the ones obtained in the sensitivity optimization section. This may be explained by the heterogeneity of the cells, which exhibit intrinsic variations in terms of diameter and position in the cell cycle. The RF measurement of individual living biological cells is therefore particularly challenging and achieved however with an excellent repeatability.
Table 2. Summary of capacitive and conductive contrasts at 5 and $40 \mathrm{GHz}$ respectively of a single polystyrene bead and a single biological cell. Standard deviations in bracket.

\begin{tabular}{|l|c|c|}
\hline $\begin{array}{l}\text { In culture } \\
\text { medium }\end{array}$ & $\Delta \mathrm{C}(\mathrm{fF}) @ 5 \mathrm{GHz}$ & $\Delta \mathrm{G}(\mathrm{mS}) @ 40 \mathrm{GHz}$ \\
\hline Single bead & $-1(0.04)$ & $-0.085(0.008)$ \\
\hline Single cell & $-0.44(0.03)$ & $-0.044(0.006)$ \\
\hline
\end{tabular}

\section{CONCLUSIONS}

The sensitivity optimization of a microwave biosensor dedicated to the single biological cell analysis directly in its culture medium has been performed and led to an important design rule to further focalize the electromagnetic fields in the cell and reach an improvement of $40 \%$ to $60 \%$ on capacitive and conductive contrasts respectively. Even if RF measurement of individual living biological cells is particularly challenging due to their ultra-small dielectric contrasts, excellent repeatability of results has been demonstrated with dielectric spectroscopy up to $40 \mathrm{GHz}$.

\section{REFERENCES}

[1] J. L. Carey, J. P. McCoy, D.F. Keren, "Flow Cytometry in Clinical Diagnosis," 4th Edition, American Society for Clinical Pathology Press, Chicago, IL, 2007, ISBN-13: 978-0891895480.

[2] Rashid Bashir, BioMEMS: state-of-the-art in detection, opportunities and prospects, Advanced Drug Delivery Reviews 56 (2004) 1565- 1586.

[3] K. Grenier, D. Dubuc et al., 'Integrated Broadband Microwave and Microfluidic Sensor dedicated to Bioengineering', IEEE Trans. on Microwave Theory and Techniques, Vol. 57, n 12 , Dec. 2009, pp. 32463253.

[4] M.M Bajestan, A.A. Helmy, H. Hedayati, K. Entesari, "A 0.62-10GHz CMOS Dielectric Spectroscopy System for Chemical/Biological Material Characterization," IEEE International Microwave Symposium, Tampa, USA, 2014.

[5] J.-C. Chien, M. Anwar, E.-C. Yeh, L. P. Lee, A. M. Niknejad, "A 6.5/17.5-GHz Dual-Channel Interferometer-based Capacitive Sensor in 65-nm CMOS for High-Speed Flow Cytometry," IEEE International Microwave Symposium, Tampa, USA, 2014.

[6] S. Anghyun, T. Stintzing, I. Block, D. Pavlidis, M. Rieke, P. G. Layer, "High frequency wideband permittivity measurements of biological substances using coplanar waveguides and application to cell suspensions", 2008 IEEE MTT-Symposium International, pp. 915 - 918, 2008.

[7] D. Di Carlo, N. Aghdam, L.P. Lee, "Single-cell enzyme concentrations, kinetics, and inhibition analysis using high-density hydrodynamic cell isolation arrays," Anal. Chem., vol. 78, pp. 4925-4930, 2006.

[8] N. Haase, A.F. Jacob, "Characterization of biological substances using a substrate integrated microwave near-field sensor," European Microwave Week 2012, Amsterdam, Netherlands, Oct. 2012.

[9] F. Artis et al., " Microwave dielectric spectroscopy for biological cells suspensions analysis and proliferation evaluation," IEEE EuMC 2014, Rome, Italy, Oct. 2014

[10] Y. Yang, P. Wang et al., "Distinguishing the viability of a single yeast cell with an ultra-sensitive radio frequency sensor, Lab on a Chip, 10, pp. 553-555, 2010.

[11] T. Chen et al, Microwave biosensor dedicated to the dielectric spectroscopy of a single alive biological cell in its culture medium, IEEE IMS (2013) 978-1-4673-2141. 